\title{
Prevalence and Risk Factors of Asthma Symptoms in Adult Sudanese Using a Modified ISAAC Questionnaire
}

\author{
Musa $\mathrm{O}^{1}$, Magzoub A ${ }^{1}$, Elsony $A^{2}$, Eltigani $\mathbf{M}^{3}$, Elmahi $G^{4}$, Elawad $A^{5}$, Dawoud $O^{6}$ \\ ${ }^{1,4}$ National Ribat University, Faculty of Medicine Dept. of Physiology, Sudan \\ ${ }^{2,3}$ Epidemiological Laboratory (Epi-Lab), Khartoum, Sudan \\ ${ }^{5}$ Elneelain University, Faculty of Medicine Dept. of Physiology,Sudan \\ ${ }^{6}$ Kassala University, Faculty of Medicine, Dept. of Physiology, Sudan
}

\begin{abstract}
Asthma prevalence in Sudanese children was found to be $12.5 \%$ as a part of the international study of asthma and allergies in children (ISAAC).The present study aimed at estimating the prevalence of asthma symptoms in different regions of Sudan and to identify risk and trigger factors influencing disease prevalence and exacerbation.. A cross-sectional study was performed in Elobeid (western), Dongola (northern), Kassala (eastern) and Khartoum (capital and central) of Sudan during 2009 - 2012. A modified ISAAC questionnaire was distributed to University students, academic staff, employee and workers chosen randomly. Any subject with asthma symptoms was interviewed by another questionnaire especially designed for asthma patients. A total of 3974 respondents (1807 males and 2167 females), aged 18 and above were included. Prevalence of asthma depending on wheezing symptom in the past 12 months was $6.7 \%$ in Elobeid, $9.6 \%$ in Dongola, 10.8\% in Khartoum, $13 \%$ in Kassala with an overall average of $10 \%$. Most of asthmatic subjects (88\%) have intermittent symptoms. Young age, first degree family history, indoor air pollution, active tobacco smoking, domestic animals and dust are the major trigger factors for asthma symptoms. In conclusion, asthma prevalence is high in adult Sudanese with some regional variation.
\end{abstract}

Keywords: Asthma, Prevalence, ISAAC, Sudan.

\section{Introduction}

The past three decades have witnessed an enormous increase in the prevalence of asthma and other allergic diseases worldwide. Genetic factors, infections, air pollution, tobacco smoking and exposure to environmental allergens have been accused as potential risk factors influencing the disease pattern [1-4]. A world map of the prevalence of asthma has been produced based on results of two large multinational studies including developing countries: The European Community Respiratory Health Survey (ECRHS) in adults and the International Study of Asthma and Allergies in Childhood (ISAAC) in children. The ECRHS study has shown large geographical differences in the prevalence of asthma with high prevalence rate in English speaking countries and low prevalence rates in the Mediterranean region and Eastern Europe [5,6].

The ISAAC study has used standardized symptom-based questionnaires in three phases to describe the prevalence of symptoms of asthma, rhinoconjunctivitis and eczema in children worldwide. The range of the prevalence of asthma symptoms for the 13/14 year age group in self reported past 12 month wheeze was very large, ranging from $2.1-4.4 \%$ in Albania, China, Greece, Georgia, Indonesia, Romania and Russia to $29.1-32.2 \%$ in Australia, New Zealand, Republic of Ireland and the UK.

In the Arab world respiratory allergy is also increasing. Studies conducted by Al-Frayh et al (1990) in Saudi Arabia indicated that the prevalence of asthma among school children in Riyadh was about $10 \%$, and ranged between $4 \%$ and $23 \%$ in different areas all over the Kingdom of Saudi Arabia [7]. In two nation-wide cross-sectional surveys, six years apart conducted in Oman (ISAAC phases I (1995) and III (2001) in two age groups (6-7 and 13-14 years) had revealed a significant increase in the prevalence of wheeze in the past 12 months from $8.7 \%$ to $13.8 \%(p=0.002)[8]$. In a study conducted in Egypt, ISAAC questionnaire was distributed to a sample of 2,645 older school children in Cairo. Prevalence of asthma depending on wheezing symptom was $14.7 \%$ and $9.4 \%$ physician-diagnosed [9]. A higher self-reported prevalence of asthma (13\%.) was also obtained in a study included 6,543 subjects in Al-Ain United Arab Emirates (UAE) with median age of 30 years [10].

In Africa, valuable information regarding prevalence patterns and potential risk factors in the development of asthma, allergic rhino-conjunctivitis and eczema was provided recently by the ISAAC study which enrolled 22 centers in 16 African countries including the Sudan [11]. The prevalence estimate rates were found to be relatively high with a number of centers showing prevalence of current wheeze similar to those reported in European countries $(12.5 \%$ in Khartoum state, central Sudan). Although the ISAAC study was based on prevalence of symptoms and included only children, yet it demonstrated for the first time that asthma is an emerging public health problem in Africa.

Data are lacking on asthma epidemiology in Sudanese adults despite the increasing number of asthma case finding in the different Sudanese health facilities. Sudan is a large country with a vast geographical, racial and socioeconomic diversity. 


\section{International Journal of Science and Research (IJSR) \\ ISSN (Online): 2319-7064 \\ Index Copernicus Value (2013): 6.14 | Impact Factor (2014): 5.611}

Therefore, differences in asthma prevalence and potential risk factors are obviously expected.

The aim of this study was to determine the prevalence of asthma symptoms in Sudanese adults and to identify risk and trigger factors influencing disease prevalence and exacerbation.

\section{Materials and Methods}

A cross-sectional study conducted during 2009 - 2012. It involved four sites in Sudan: Khartoum (capital of Sudan), Dongola (northern Sudan), Elobeid (western Sudan), and Kassala (eastern Sudan). The participants were adult Sudanese University students, staff, employees and workers, males and females aged 18 and above living in the study site for more than one year. Samples were taken using a multistage random sampling. The total universities in the four sites under study were 27 distributed as follows: Khartoum state (18 universities); western Sudan states (4 universities) northern Sudan (3 universities) and eastern Sudan (2 universities). Khartoum state population is the largest compared to rest of the sites which explain the large number of universities.

Out of the 18 universities in Khartoum, 3 universities were chosen randomly and one university was included from each of the 3 remaining sites. In each randomly chosen university, faculties were firstly randomly selected from a list of all university faculties, then the staff, employees and workers were randomly selected from lists of names and the students were randomly selected form the registered lists. A total of 3974 respondents were included.

\section{The questionnaire}

A modified translated International Study of Asthma and Allergy in Childhood (ISAAC) questionnaire for adults was filled out by all the chosen participants. The questionnaire covered personal data, asthma symptoms, allergy symptoms and environmental factors. An additional questionnaire especially designed for asthma was filled by all those with positive response to asthma symptoms. It contains asthma history, diagnosis, symptoms severity, medications, past medical history of allergic diseases and chronic illness; family history of asthma and allergy; habits and trigger factors for asthma symptoms. Asthma severity grade was classified according to the IUTLD (The Union) classification into intermittent (less than weekly symptoms); mild persistent asthma (weekly symptoms), moderate persistent (daily symptoms) and severe persistent (continuous symptoms).

\section{Data Analysis and Statistics}

Data were entered into SPSS software (Statistical Package for Social Science program), version 16. Chi-square was used to compare differences in proportions between groups (Odds ratios with 95\% confidence intervals). Differences at $5 \%$ level $(\mathrm{p}<0.05)$ were regarded as significant.

\section{Ethical Approval}

The study was approved by the Research Ethics Committee of the National Ribat University, Khartoum, Sudan. All participants were informed about the objectives and the need of this study; self confidentiality was assured and their consent to participate was taken.

\section{Results}

\section{Demography}

The study included 3794 subjects, 1807 (45.5\%) were males and $2167(54.5 \%)$ were females recruited from four sites in the Sudan: Elobeid (west), Dongola (north), Kassala (east) and Khartoum (central Sudan). Young adults group (18 - 27 years) was the commonest one seen in the total sample (73.6\%), among which, university students were the highest number included 3387 (85.2\%).

\section{Asthma Prevalence, Risk, and Trigger Factors}

Prevalence of asthma symptoms depending on wheeze in the past 12 months was $6.7 \%$ in Elobeid, 9.6\% in Dongola, $10.8 \%$ in Khartoum, and $13 \%$ in Kassala with an average of $10 \%$ in the total sample (fig. 1). Physician diagnosed asthma was $2 \%$ in the total sample. Asthma symptoms were slightly more prevalent in females in the total sample (11\%) than in males (10\%). Wheezing was the most prevalent asthma symptom in all study sites and total sample (90\%) followed by cough at night $(63 \%)$ and shortness of breath during the day (55\%), (fig.2). Most of asthmatic subjects have intermittent symptoms (fig.3). Risk factors for asthma symptoms included: young age $(60.7 \%-81 \%$ of asthmatics were in the age group (18 - 27 years); family history of asthma in a first degree relative; indoor air pollution particularly in rural sites; active tobacco smoking which was found more related to Shisha than cigarette smoking; domestic animals; plants; dust and food (table-1).

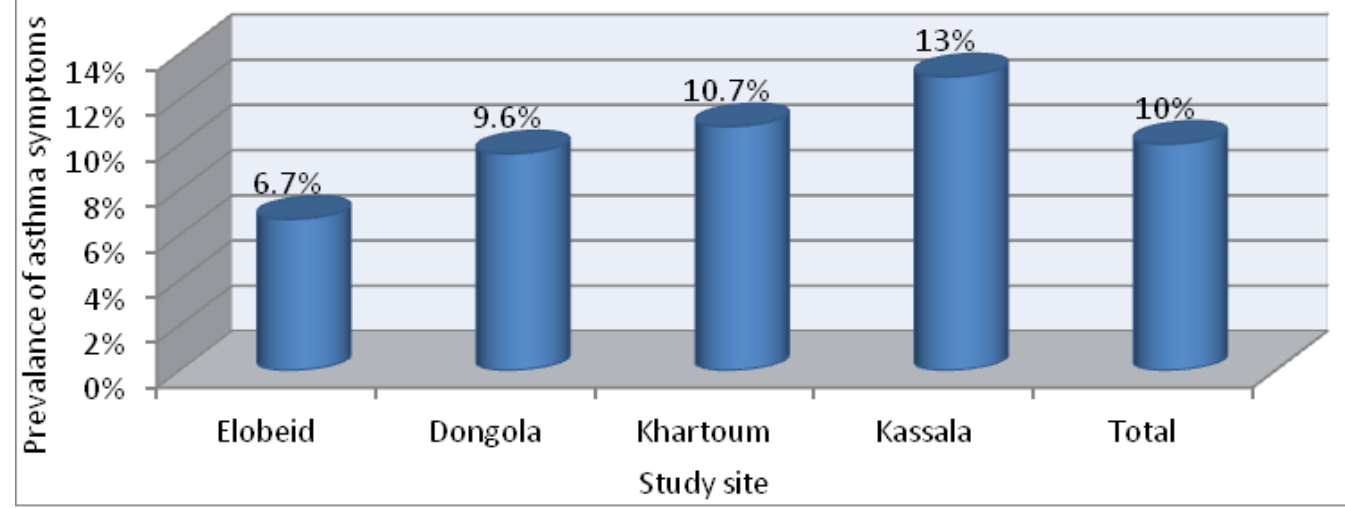

Figure 1: Prevalence of asthma symptoms depending on wheeze in the past 12 months 


\section{International Journal of Science and Research (IJSR) \\ ISSN (Online): 2319-7064}

Index Copernicus Value (2013): 6.14 | Impact Factor (2014): 5.611

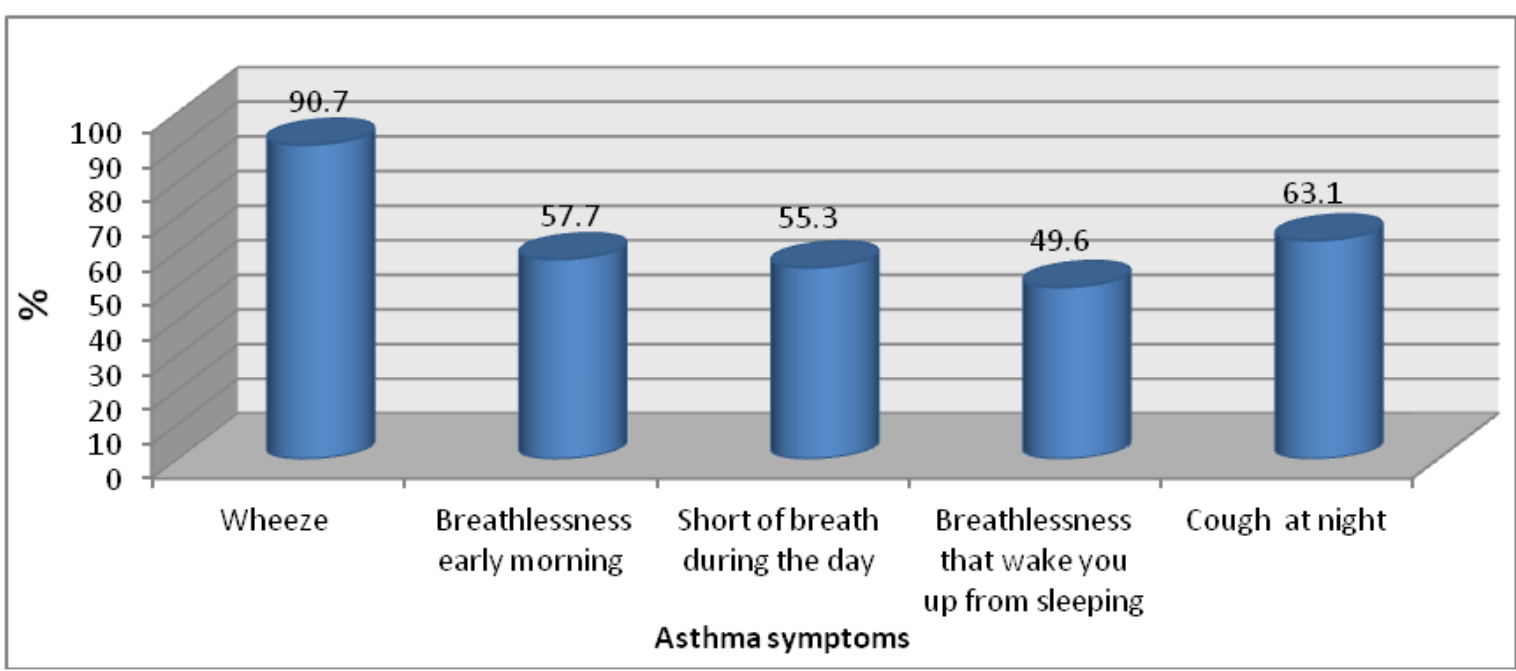

Figure 2: Distribution of asthma symptoms in the asthmatics

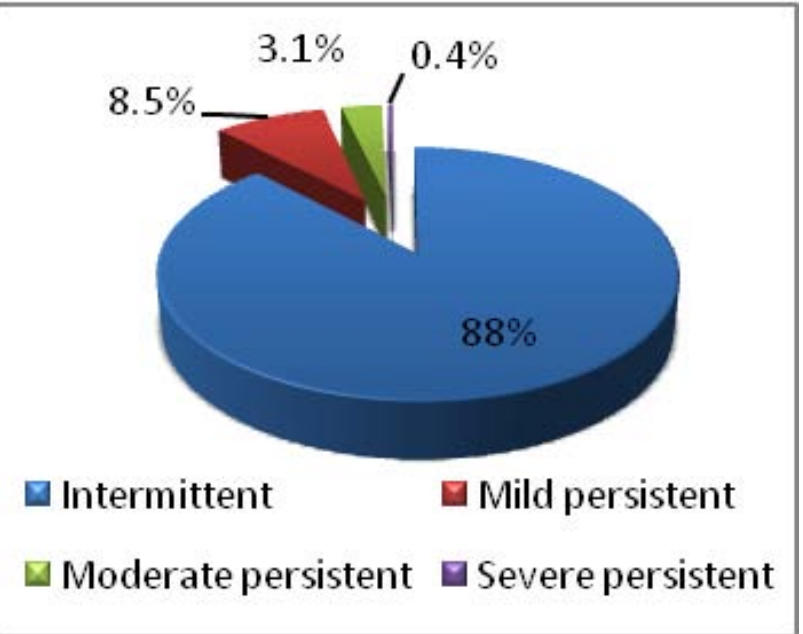

Figure 3: Asthma severity grade (based on The Union classification of asthma severity grade)

Table 1 Risk and trigger factors for asthma symptoms in adult Sudanese.

\begin{tabular}{|c|c|}
\hline Risk or trigger factor & Odds ratio \\
\hline Positive family history of asthma & 1.85 (East) -4.98 (West) \\
\hline Tobacco smoking & 0.83 (East) -2.5 (West) \\
\hline Tobacco smoking (Shisha) & 1.12 (Capital) -4.10 (West) \\
\hline Indoor air pollution & 2.34 (Rural) \& 1.17 (Urban) \\
\hline Domestic animals & 1.46 (East) -7.07 (west) \\
\hline Plants & 1.89 (Capital) -2.99 (North) \\
\hline Dust & $1.61($ Capital $)-3.17$ (West) \\
\hline Food & 1.65 (East) -4.06 (West \& North) \\
\hline
\end{tabular}

\section{Discussion}

This survey is designed to determine asthma prevalence in adults in Sudan. The total sample of respondents (3974 subjects) is consistent with ECRHS protocol for asthma prevalence in adults which recommends inviting at least 3000 subjects for questionnaire study. Females were more than males in the total recruited subjects because of the recent increased rate of female intake in Sudanese universities.

In the present study, prevalence of asthma depending on wheezing in the past 12 months as guided by the ISAAC study ranged from $6 \%$ in Elobeid (western Sudan) to $13 \%$ in
Kassala (eastern Sudan) with an average prevalence of $10 \%$ in the total sample which was consistent with international and regional studies adopting similar methods [12, 13], but to some extent higher than other surveys using other methods e.g physician diagnosed asthma. Because of the few studies, data on asthma prevalence in adults are scarce in Arab as well as in African countries. In a Jordanian school children survey, the reported wheezing prevalence was $8.3 \%$, but physician diagnosed asthma was $4.1 \%$ [14]. In European adults, asthma prevalence ranged from $5 \%$ to $10 \%$ [15], and among US adults ranged geographically from $8.6 \%$ (northeast) to 10.5 in the western part [16].

Urbanization, genetic, climatic and socioeconomic difference could explain the regional variation in the prevalence, risk and trigger factors for asthma symptoms in Sudan (fig.1 \& table-1). This variation in asthma prevalence gives a clue to the pathogenesis of asthma and allergy, which might be due to disparity in genetics due to population diversity [17], differences in lifestyle [18], including dietary factors [19], or differences in outdoor or indoor allergens exposure [20].

Females were slightly more affected than males in the total asthmatics sample which is consistent with many studies conducted in asthma prevalence in adults [21-23].However, the regional gender variation in asthma prevalence is in concordance with some studies which have found a weaker independent association with female sex and nearly 2:1 male to female ratio in a recent Nigerian study in adults [24].

Intermittent asthma grade is representing $88 \%$ of the total asthmatic subjects according to symptom classification.

The limitation in our study is about its generalization to the whole community as our sample size is mainly University students in the age group 16-27 years. However, when we did a pilot community prevalence survey including randomly selected 121 adult subjects from four sites in Elobied, it showed a prevalence of current wheeze of $10.7 \%$ which is slightly higher than the present survey using University students and workers in Elobeid but is almost similar to general prevalence for Sudanese adults $(10 \%)$. Nevertheless, the University students and staff actually represent the Sudanese community as it is open for anyone to join. 


\section{International Journal of Science and Research (IJSR) \\ ISSN (Online): 2319-7064}

Index Copernicus Value (2013): 6.14 | Impact Factor (2014): 5.611

In conclusion, prevalence of asthma symptoms depending on current wheezing is high in adult Sudanese with interregional variation. Modern lifestyle, indoor air pollution, positive family history, active tobacco smoking, domestic animals and dust are the major risk or trigger factors for asthma symptoms. Most of the patients have intermittent symptoms that need only reliever drugs and only $4 \%$ have moderate to severe asthma. This implies that the need for continuous inhaled corticosteroids for these groups is not a major problem as they represent only $0.4 \%$ of the Sudanese population.

\section{References}

[1] Von Hertzen LC, Haahtela T. Signs of reversing trends in prevalence of asthma. Allergy 2005; 60:283-292.

[2] Toelle BG, Ng K, Belousova E, Salome CM, Peat JK, marks GM. Prevalence of asthma and allergy in school children in Belmont, Australia: three cross sectional surveys over 20 years. BMJ 2004; 328:386-387.

[3] Global initiative for asthma. Global strategy for asthma management and prevention. NHLBI/WHO workshop report. National Heart, Lung, and Blood Institute Publication 95-3659. Bethesda, MD, USA: National Institutes of Health, January1995.Revised in 2006.

[4] Masoli M, Fabian D, Holt S, Beasley R. Global Burden of Asthma. Developed for the Global Initiative for Asthma (GINA). Available from: http://www.ginasthma.com

[5] Burney PG, Luczynska CM, Chinn S, Jarvis D. The European Community Respiratory

[6] Health Survey. Eur Respir J 1994; 7:954 -960.

[7] Janson C, Anto J Burney P, Chinn S, Marcoz R, J. Heinrich $\mathrm{J}$ et al. European community Respiratory health survey: What are the main results so far? Eur Respir J 2001; 18: 598-611

[8] Al-Frayh AR. Asthma pattern in Saudi Arabian children. J. Royal Soc. Health 1990; 3: 98-100.

[9] Omar A, Bazdawi M, Hussein A, Abdullah A, and Asya A. Regional Variation in the Prevalence of Asthma Symptoms among Omani School Children Comparisons from Two Nationwide Cross-sectional Surveys Six Years Apart .Sultan Qaboos Univ Med J. 2008 July; 8(2): 157-164.

[10] Georgy V, Fahim H, Gaafary $M$ and Walters S. Prevalence and socioeconomic associations of asthma and allergic rhinitis in northern Africa Eur Respir J 2006; 28: $756-762$.

[11] Shirina A,Abdishakur and A Roos B. Prevalence and Risk Factors of Asthma among Adolescents and Their Parents in Al-Ain UAE. Respiration 2010; 79:105-111.

[12] Ait-Khalid N, Odihambo J, Pearce N, Adjoh KS, Maesano IA, Benhabyles B, Camara L, Catteau C, El Sony A, Hypolite IE, Musa OA et al . Prevalence of symptoms of asthma, rhinitis and eczema in 13 to 14 year old children in Africa: the International Study of Asthma and Allergy (ISAAC) in Childhood Phase III .Allergy. 2007 Mar; 62(3):247-58.

[13] Aggarwal AN, Chaudhry K, Chhabra SK, D'Souza GA, Gupta D, Jindal SK et al. Prevalence and risk factors for bronchial asthma in Indian adults: a multicentre study. Indian J Chest Dis Allied Sci. 2006 Jan-Mar; 48(1):1322.
[14] Erhabor GE, Agbroko SO, Bamigboye P, Awopeju OF. Prevalence of asthma symptoms among University students 15 to 35 years of age in Obafemi Awolowo University, Ile-Ife, Osun State. J Asthma. 2006 Mar; 43(2):161-4.

[15] Abuekteish F, Alwash R, Hassan M, Daoud AS. Prevalence of asthma and wheeze in primary school children in northern Jordan. Ann Trop Paediatr. 1996 Sep; 16(3):227-31.

[16] Adams PF, Hendershot GE, Marano MA. Current estimates from the National Health Interview Survey, 1996. Vital Health Stat 10. 1999 Oct ;(200):1-203.

[17] Rose D, Mannino DM, Leaderer BP. Asthma prevalence among US adults, 1998-2000: role of Puerto Rican ethnicity and behavioral and geographic factors. Am J Public Health. 2006 May; 96(5):880-8

[18] Kivity S, Sade K, Abu-Arisha F, Lerman Y, Kivity S. Epidemiology of bronchial asthma and chronic rhinitis in schoolchildren of different ethnic origins from two neighboring towns in Israel. Pediatr Pulmonol. 2001 Sep; 32(3):217-21.

[19] von Mutius E, Martinez FD, Fritzsch C, Nicolai T, Roell G, Thiemann HH. Prevalence of asthma and atopy in two areas of West and East Germany. Am J Respir Crit Care Med. 1994 Feb;149:358-64

[20]Hijazi N, Abalkhail B, Seaton A. Diet and childhood asthma in a society in transition: a study in urban and rural Saudi Arabia. Diet and childhood asthma in a society in transition: a study in urban and rural Saudi Arabia.

[21] Burr ML, Limb ES, Andrae S, Barry DM, Nagel F. Childhood asthma in four countries: a comparative survey. Int J Epidemiol. 1994 Apr; 23(2):341-7.

[22] Almqvist C, Worm M, Leynaert B. Impact of gender on asthma in childhood and adolescence. Allergy. 2008 Jan; 63(1):47-57. Epub 2007 Sep 5.

[23] Postma DS. Gender differences in asthma development and progression. Gend Med. 2007; 4 Suppl B: S133-46.

[24]Bjornson CL, Mitchell I. Gender differences in asthma in childhood and adolescence. J Gend Specif Med. 2000 Nov-Dec; 3(8):57-61.

[25] Desalu OO, Oluboyo PO, Salami AK. The prevalence of bronchial asthma among adults in Ilorin, Nigeria. Afr $\mathrm{J}$ Med Med Sci. 2009 Jun; 38(2):149-54. 